inflammation, traditional CVD risk factors and metabolic disease have been suggested, but no full explanation is currently present.

Objectives: In this prospective case-control study, we investigated how the progression of subclinical atherosclerosis is associated with CVD risk factors and parameters of inflammation in patients with RA compared with matched controls. Methods: By the time of diagnosis, patients from northern Sweden diagnosed with early RA are consecutively recruited into an ongoing prospective study. From these, a subgroup aged $\leq 60$ years was consecutively included for ultrasound measurements of intima media thickness (IMT) of a. carotis communis at inclusion (T0) $(n=79)$, after 5 years (T5) ( $n=71)$ and after 11 years $(T 11)(n=55)$. 44 age-sexmatched controls were included and 31 could be revaluated at T11. Pharmacological treatment, previous CVD, markers of inflammation, lipid status, blood pressure, body mass index as well as measurements of disease activity were registered. Any previous CV events were verified by medical records. European Systematic Coronary Risk Evaluation (SCORE) and Reynolds Risk Score were calculated and Larsen score (of hands and feet) were registered. IMT progression rate ( $\triangle \mathrm{IMT}$ T0-T11) was calculated by subtracting baseline values from IMT after eleven years follow up.

Results: IMT increased significantly between T0 and T11 among patients with RA (IMT T0: $0.51(0.12)$ T11: 0.68 (0.16) p<0.0001) and controls (IMT T0: 0.54 $(0.12) \mathrm{T} 11: 0.63(0.13) p<0.0001)$. There was a higher progression rate between T0 and T11 in the RA group compared with the controls $(\mathrm{p}<0.05)$. In simple regression models, IMT T11 was significantly associated with several traditional CVD risk factors as well as Larsen score at T0 among RA patients (table 1). Moreover, in simple regression models $\triangle I M T$ T0-T11 was significantly associated with Larsen score and age at T0 (both $p<0.01$ ) among patients with RA. A multiple regression model, with $\triangle \mathrm{IMT}$ T0-T11 as dependent variable, including traditional CVD risk factors at T0 (age, systolic blood pressure (BP), cholesterol and smoking), resulted in a $\mathrm{R} 2$ of 0.32 where age and cholesterol ( $\mathrm{p}<0.01$ for both) were significantly associated with $\triangle \mathrm{IMT} T 0-\mathrm{T} 11$. When also adding CRP and Larsen score the R2 increased to 0.50 and age $(p<0.05)$ and Larsen score $(p<0.01)$ were significantly associated with IMT T11.

Abstract THU0158 - Table 1. Simple regression models among 55 patients with RA with IMT after 11 years of follow up as the dependent variables.

\begin{tabular}{lccc}
\hline Variable & \multicolumn{3}{c}{ IMT T11 } \\
\hline \multicolumn{1}{c}{$\beta$} & $95 \% \mathrm{Cl}$ & $\mathrm{p}$ \\
\hline Age, T0 & $0.104 /$ year & $0.071-0.136$ & $<0.001$ \\
Systolic BP, T0 & $0.035 /$ & $0.009-0.061$ & $\mathbf{0 . 0 0 9}$ \\
& $\mathrm{mmHg}$ & & \\
SCORE, T0 & $0.534 /$ unit & $0.261-0.807$ & $<0.001$ \\
Reynolds risk score, & $0.182 /$ unit & $0.048-0.315$ & $\mathbf{0 . 0 0 9}$ \\
T0 & & & \\
Larsen score, T0 & $0.122 /$ unit & $0.004-0.239$ & $\mathbf{0 . 0 4 3}$ \\
DAS 28, T0 & $-0.236 /$ unit & $-0.771-$ & 0.364 \\
& & 0.298 & \\
\hline
\end{tabular}

Conclusions: In this prospective study, we found that there was an increased progression of atherosclerosis among RA patients, compared with controls, eleven years after diagnosis, and that this increase is associated with Larsen score and age at baseline.

Disclosure of Interest: None declared

DOI: 10.1136/annrheumdis-2018-eular.2831

\section{THU0159 BARRIERS TO RHEUMATOID ARTHRITIS TREATMENT OPTIMISATION: REAL-WORLD DATA FROM THE ARTHRITISPOWER REGISTRY}

J.L. Stark' ${ }^{1}$ M. Yassine ${ }^{1}$, W.B. Nowell ${ }^{2}$, K. Gavigan ${ }^{2}$, S. Ginsberg ${ }^{2}$, M.S. Serna ${ }^{1}$, J. R. Curtis ${ }^{3} .{ }^{1}$ UCB Pharma, Smyrna, GA; ${ }^{2}$ Global Healthy Living Foundation, Upper Nyack, NY; ${ }^{3}$ University of Alabama at Birmingham, Birmingham, AL, USA

Background: Few research studies have investigated treatment $(T x)$ goals in rheumatoid arthritis (RA) from the patients' (pts) perspective, including factors preventing achievement of Tx targets and reasons why pts tolerate sub-optimal disease control.

Objectives: To identify barriers to Tx optimisation, using real-world data from the ArthritisPower registry. Secondary objectives were to understand pts' Tx goals and why pts tolerate active disease.

Methods: This was an observational, cross-sectional sub-study of pts in the ArthritisPower registry. Pts were aged $\geq 19$ years, had physician-diagnosed RA, no change to $T x$ within 3 months of baseline, and had access to a computer/smartphone. Pt-reported outcomes (PROs) included pain, fatigue, sleep, physical function, and general health. Pts also completed an online survey on barriers to $\mathrm{Tx}$ escalation, and were classified into 3 groups based on physician and pt attitudes to Tx change (change not offered, change offered and accepted, change offered and rejected). Disease activity was reported using Routine Assessment of Patient Index Data 3 (RAPID3) scores.

Results: 257 pts met the inclusion criteria (table 1). 195/257 (76\%) pts were treated with DMARDs (non-biologic or biologic). 180/257 (70\%) pts had high disease activity by RAPID3 (median 18.0 on $0-30$ scale), of which only $67 / 180$ (37\%) were offered a Tx change at their last physician visit. Most of these pts accepted the Tx change (48/67 [72\%]). There were few differentiating factors in demographics, RA-related features, and background therapy among pts who were offered a Tx change versus not. Most pts (33/44 [75\%]) who intensified Tx did so because their symptoms remained bad or worsened, whereas only $16 / 44(36 \%)$ changed because they did not reach pre-defined Tx goals. The most common reason $(21 / 32[66 \%])$ for deciding not to change therapy was the rheumatologist's satisfaction with the current therapy; pt concerns related to safety of the new therapy were less common $(8 / 32[25 \%])$. There was a weak correlation between the RAPID3 score and pts' self-reported perception of their own disease activity. The majority of pts (176/257 [69\%]) valued being actively involved in making decisions with their doctor about $\mathrm{Tx}$

Abstract THU0159 - Table 1. Patient demographics at baseline

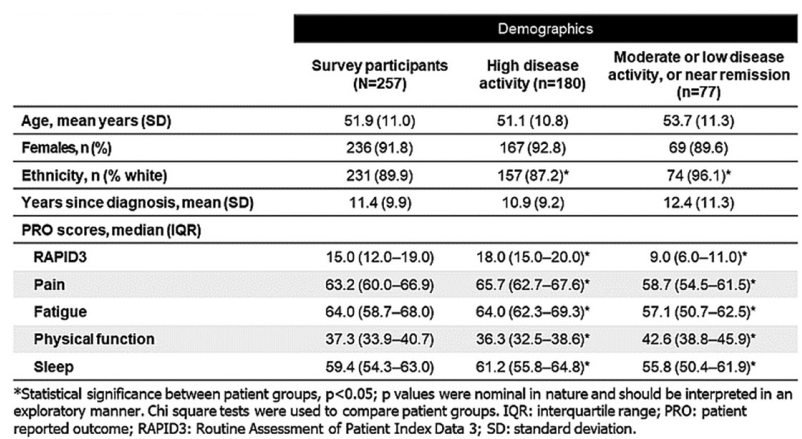

Conclusions: Despite treat-to-target recommendations, ${ }^{1}$ about two-thirds of RA pts with high disease activity in this sample were not offered a Tx change by thei rheumatologist. Only a minority changed because they had not met predefined targets for disease control. Pts commonly followed their rheumatologist's decision that no Tx change was needed and placed greater importance on their doctor's Tx goals than their own. These findings suggest that pts may be more deferential to their physicians' satisfaction with poor RA disease control than is appropriate. Encouraging pts (not just physicians) to overcome the status quo by changing medications and striving for low disease activity/remission may be worthwhile, but traditional metrics (e.g. RAPID3) may not reflect the most relevant target for pts' goals for therapy.

\section{REFERENCE:}

[1] Stoffer M. Ann Rheum Dis 2016;75(1):16-22.

Acknowledgements: This study was funded by UCB Pharma. We thank the patients and their caregivers in addition to the investigators and their teams who contributed to this study. Editorial services were provided by Costello Medical. Disclosure of Interest: J. L. Stark Employee of: UCB Pharma, M. Yassine Employee of: UCB Pharma, W. B. Nowell: None declared, K. Gavigan: None declared, S. Ginsberg: None declared, M. S. Serna Employee of: UCB Pharma, J. R. Curtis Grant/research support from: Amgen, BMS, Janssen, Myriad Genetics, Lilly, Novartis, Pfizer, Roche and UCB Pharma, Consultant for: Amgen, BMS, Janssen, Myriad Genetics, Lilly, Novartis, Pfizer, Roche and UCB Pharma DOI: 10.1136/annrheumdis-2018-eular.2314

\begin{tabular}{|l|l}
\hline THU0160 & JUXTA-ARTICULAR BONE HEALTH AFFECTS NEW \\
CAROTID PLAQUE FORMATION INDEPENDENT WITH \\
GLUCOCORTICOID THERAPY IN POSTMENOPAUSAL \\
PATIENTS WITH RHEUMATOID ARTHRITIS
\end{tabular}

J.W. Kang, N.R. Kim, J.S. Eun, J.H. Kim, J.Y. Kang, J.S. Seo, G.B. Bae, S.J. Lee, E.J. Nam, Y.M. Kang. Division of Rheumatology, Department of Internal Medicine, Kyungpook National University School of Medicine, Daegu, Korea, Republic of Ireland

Background: Rheumatoid arthritis (RA) is a chronic and systemic inflammatory disease.

The incidence of cardiovascular (CV) disease is increased in patients with RA, compared with the general population, which is related to the fact that atherosclerosis has an inflammatory etiology. 
Several studies revealed that RA is associated with systemic bone loss, and longterm glucocorticoid therapy is also known to affect CV events as well as bone health such as osteoporosis.

Especially in postmenopausal women, the prevalence of osteoporosis and its complications are important medical issues.

Objectives: In the present study, we investigated the bone mineral density (BMD) for the carotid plaque formation in RA patients in the Kyungpook National University Hospital Atherosclerosis Risk in Rheumatoid Arthritis (KARRA) cohort study.

Methods: After a baseline evaluation for KARRA enrollment, RA patients were prospectively followed up for 5 years or until deaths.

We analysed the demographic findings, conventional CV risk factors and RA disease activity.

Carotid ultrasound at baseline and year 5 was performed to evaluation of the intima-medial thickness (IMT) and presence and progression of carotid plaque.

A total 323 patients (272 female) with RA, who performed dual-photon x-ray absorptiometry and carotid ultrasound, were included.

We assessed disease activity of RA, risk factors for atherosclerosis including hypertension, diabetes mellitus and dyslipidemia, presence of carotid plaque, BMD and cumulative glucocorticoid doses.

Results: A total of 417 RA patients were included in the baseline KARRA cohort, and 327 patients with RA were followed for the 5 year period.

Of the 417 baseline RA patients, 212 patients had no carotid plaque. At year 5 , new carotid plaque formation was found in 91 of 214 patients who underwent BMD examination.

The BMD in the l-spine, femur, and radius was significantly lower in patients with carotid plaques $(n=154)$, compared to patients without plaques $(n=172)(1.016 \mathrm{~g} /$ $\mathrm{cm} 2 \pm 0.22$ vs. $1.066 \pm 0.18, p=0.013$ for I-spine; $0.817 \pm 0.15$ vs. $0.865 \pm 0.14$ $\mathrm{p}<0.001$ for femur; $0.542 \pm 0.14$ vs. $0.605 \pm 0.13, p<0.001$ for radius

In postmenopausal patients, the BMD was significantly lower in carotid plaque group $(n=93)$ than non-plaque group $(n=109)(0.962 \pm 0.171$ vs. $1.056 \pm 0.174$, $\mathrm{p}<0.001$ for $\mathrm{L}$ spine; $0.780 \pm 0.14$ vs. $0.857 \pm 0.12, \mathrm{p}<0.001$ for femur; $0.502 \pm 0.110$ vs. $0.593 \pm 0.112, p<0.001$ for radius).

The cumulative steroid dose was confirmed in postmenopausal female patients, and the glucocorticoid dose was correlated with new carotid plaque formation. $(r=0.334, p=0.04)$. Multivariate logistic regression analysis revealed that but radius BMD $(p=0.04)$ was independent risk factors for new carotid plaque formation during the 5 year followed period after correlation with cumulative glucocorticoid dose, but I-spine ( $p=0.06)$ and femur BMD ( $p=0.07)$ were not statistically significant.

Conclusions: This study shows formation of new plaques after long-term followup depends on the juxta-articular bone health in postmenopausal RA patients.

Disclosure of Interest: None declared

DOI: 10.1136/annrheumdis-2018-eular.6694

\section{\begin{tabular}{|l|l}
\hline THU0161 TRENDS IN THE INCIDENCE OF AMYLOIDOSIS IN \\
\hline
\end{tabular} PATIENTS WITH RHEUMATOID ARTHRITIS IN SPAIN: AN OBSERVATIONAL COHORT STUDY OF HOSPITAL DISCHARGES FROM 1999 TO 2015 (TREND-AR STUDY)}

J.L. Morell Hita ${ }^{1}$, R. Mazzucchelli ${ }^{2}$, E. Perez Fernandez ${ }^{3}$, J. Quiros ${ }^{2}$, C. Macía Villa $^{4}$, N. Crespi ${ }^{5}$, M. Peña ${ }^{2}$, C. Barbadillo ${ }^{6}$, M. Espinosa ${ }^{6}$, H. Godoy $^{6}$, M. Fernandez Prada ${ }^{7}$, M. Galindo ${ }^{8}$, A. Garcia Vadillo ${ }^{9}$, O. Guzon Illescas ${ }^{2}$ A. Herranz ${ }^{10}$, C. Martinez Prada ${ }^{11}$, C. Morado Quiñoa ${ }^{11}$, V. Villaverde ${ }^{12}$, on behalf of TREND-AR. ${ }^{1}$ Rheumatology, Hospital Universitario Ramón y Cajal; ${ }^{2}$ Rheumatology; ${ }^{3}$ Hospital Universitario Fundación Alcorcón; ${ }^{4}$ Rheumatology, Hospital Universitario Severo Ochoa; ${ }^{5}$ CS La Rivota; ${ }^{6}$ Rheumatology, Hospital Universitario Puerta de Hierro, Madrid; ${ }^{7}$ Rheumatology, Hospital Universitario de Guadalajara, Guadalajara; ${ }^{8}$ Rheumatology, Hospital Universitario Doce de Octubre; ${ }^{9}$ Rheumatology, Hospital Universitario La Princesa; ${ }^{10}$ Rheumatology, Hospital del Henares; ${ }^{11}$ Rheumatology, Hospital Universitario Clínico San Carlos; ${ }^{12}$ Rheumatology, Hospital Universitario Móstoles, Madrid, Spain

Background: Treatment and evolution of Rheumatoid Arthritis (RA) have had an important change in the last years. However the trend of amyloidosis, habitually related to long-standing and active RA, in Spain is unknown.

Objectives: To analyse the incidence and trend of hospital admissions for amyloidosis in RA patients in Spain from 1999 to 2015.

Methods: We performed an observational retrospective population study analysing the spanish administrative database that includes a Minimun Basic Data Set (MBDS) of hospital admissions of RA patients from 1999 to 2015. We selected the MBDSs for amyloidosis. Cases were identified by the presence in primary and secondary diagnosis of its ICD9 code. The population at risk was estimated with an estimated prevalence of RA of $0,5 \%$ ( $0,8 \%$ women and $0,2 \%$ men). Crude and adjusted rates were calculated, and the trend was analysed using the Generalised Linear Model (GLM) with the year as the analysis variable. SPSS version 20 (SPSS Inc, Chicago, IL) was used.
Results: 338.343 RA hospital admissions were detected, being $3085(0,9 \%)$ due to amyloidosis with 2298 (74,5\%) women and 787 (25,5\%) men. Mean age 65,42 (SD 13,08). There were 366 (11,9\%) deaths. Age-adjusted rate during the period was $122,87 / 10^{5}$ inhab. per year (98,96 women and 146,79 men). Amyloidosis age-adjusted rate decreased from $138,88 / 10^{5}$ inhab. per year in 1999 to 71,47 in 2015 , both women $(128,18$ in 1999 to 61,35 in 2015) and men (162,36 in 1999 to 107,95 in 2015). An annual decrease in the amyloidosis rate of $4,6 \%$ is estimated (RRI 0,953; Cl 95\% 0,939-0,968).

Conclusions: In Spain from 1999 to 2015 amyloidosis hospital admissions in patients with RA decreased, with an estimation of $4,6 \%$ annual reduction. This finding concurs with a greater knowledge of RA and its treatment advances with "treat-to-target" strategies.

Disclosure of Interest: None declared

DOI: 10.1136/annrheumdis-2018-eular.4812

\section{THU0162 RESIDUAL SYNOVITIS IN ANKLES AND FEET DETECTED BY ULTRASONOGRAPHY IN PATIENTS WITH RHEUMATOID ARTHRITIS}

J. Inamo, Y. Kaneko, K. Sakata, T. Takeuchi. Division of Rheumatology, Department of Internal Medicine, Keio University School of Medicine, Tokyo, Japan

Background: Twenty eight joints that are usually evaluated for disease activity score of rheumatoid arthritis (RA) do not include ankles and metatarsophalangea joints. Although foot synovitis of patients in remission is clinically important in that it associates to relapse and worse physical function, ${ }^{1}$ composite markers without an assessment of foot have demonstrated poor performance in detecting foot synovitis. $^{2}$

Objectives: The aim of this study was to investigate the frequency and impact of residual synovitis in ankles and feet in patients with $R A$.

Methods: Patients with RA who underwent both physical examination and ultrasonography (US) on 44 joints including hands, fingers, ankles, and metatarsophalangeal joints between April 2016 and January 2018 in Keio University Hospital were enrolled. We compared patients with swollen joints of feet and ankles and those without, and then analysed those who did not have swollen joints by physical examination but were detected to have synovitis by US

Results: Sixty one patients were enrolled in the study. The mean age was 58.5 years old, the disease duration was 7.1 years, and $85 \%$ were female. Among them, 21 patients had joint swelling in feet and ankles and 40 patients did not by physical examination. The patients in the former group showed significantly higher disease activity (DAS28 4.0 vs $2.4, \mathrm{p}<0.05$ ), higher doctor visual analogue scale (VAS, 33 vs $8 \mathrm{~mm}, \mathrm{p}<0.05)$ and higher serum matrix metalloproteinase (MMP) -3 (165 vs $51 \mathrm{mg} / \mathrm{dL}, \mathrm{p}<0.05$ ). In the 40 patients with no swollen joints in ankles and feet by physical examination, $24(60 \%)$ had active synovitis detected by US in those joints (US positive group) and the other 16 patients showed no synovitis in ankles and feet by US (US negative group). Whereas age and disease duration were not different between two groups, body mass index tended to be higher in the US positive group than the US negative group. Although the majority of both groups were in remission according to DAS28, fewer patients in the US positive group achieved remission according to Boolean criteria ( $29 \%$ vs $63 \%, p<0.05$ ) The residual disease activity in ankles and feet was reflected in pain visual analogue scale most sensitively ( $33 \mathrm{~mm}$ vs $9 \mathrm{~mm}, \mathrm{p}<0.05$ ). The discordance in globa assessments between patient and estimator of more than $30 \mathrm{~mm}$ was significantly frequent in the US positive group than the US negative group (33\% vs $6 \%$, $\mathrm{p}<0.05)$.

Conclusions: The residual synovitis in ankles and feet did not reflect in remission criteria by DAS28 but did by Boolean criteria. It caused a discordance in global assessments between patient and estimator.

\section{REFERENCES}

[1] Wechalekar MD, Lester S, Hill CL, Lee A, Rischmueller M, Smith MD, Walker JG, Proudman SM. Active Foot Synovitis in Patients With Rheumatoid Arthritis: Unstable Remission Status, Radiographic Progression, and Worse Functional Outcomes in Patients With Foot Synovitis in Apparent Remission. Arthritis Care Res (Hoboken) 2016;68(11):1616-1623.

[2] Wechalekar MD1, Lester S, Proudman SM, Cleland LG, Whittle SL, Risch mueller M, Hill CL. Active foot synovitis in patients with rheumatoid arthritis: applying clinical criteria for disease activity and remission may result in underestimation of foot joint involvement. Arthritis Rheum 2012;64 (5):1316-22.

Disclosure of Interest: None declared DOI: 10.1136/annrheumdis-2018-eular.3381 